\title{
Combination treatments with immunotherapy in brain metastases patients
}

Citation for published version (APA):

Henon, C., Remon, J., \& El Hendriks, L. (2020). Combination treatments with immunotherapy in brain metastases patients. Future Oncology, 16(23), 1691-1705. https://doi.org/10.2217/fon-2020-0156

Document status and date:

Published: 01/08/2020

DOI:

10.2217/fon-2020-0156

Document Version:

Publisher's PDF, also known as Version of record

Document license:

Taverne

Please check the document version of this publication:

- A submitted manuscript is the version of the article upon submission and before peer-review. There can be important differences between the submitted version and the official published version of record.

People interested in the research are advised to contact the author for the final version of the publication, or visit the DOI to the publisher's website.

- The final author version and the galley proof are versions of the publication after peer review.

- The final published version features the final layout of the paper including the volume, issue and page numbers.

Link to publication

\footnotetext{
General rights rights.

- You may freely distribute the URL identifying the publication in the public portal. please follow below link for the End User Agreement:

www.umlib.nl/taverne-license

Take down policy

If you believe that this document breaches copyright please contact us at:

repository@maastrichtuniversity.nl

providing details and we will investigate your claim.
}

Copyright and moral rights for the publications made accessible in the public portal are retained by the authors and/or other copyright owners and it is a condition of accessing publications that users recognise and abide by the legal requirements associated with these

- Users may download and print one copy of any publication from the public portal for the purpose of private study or research.

- You may not further distribute the material or use it for any profit-making activity or commercial gain

If the publication is distributed under the terms of Article $25 \mathrm{fa}$ of the Dutch Copyright Act, indicated by the "Taverne" license above, 


\title{
Combination treatments with immunotherapy in brain metastases patients
}

\author{
Clemence Henon', Jordi Remon² \& Lizza EL Hendriks*,3 (iD) \\ ${ }^{1}$ Department of Medical Oncology, Gustave Roussy Cancer Campus, Institut d'Oncologie Thoracique (IOT), Gustave Roussy, \\ Villejuif, France \\ ${ }^{2}$ Department of Medical Oncology, Centro Integral Oncológico Clara Campal (HM CIOCC), Hospital HM Delfos, HM Hospitales, \\ Barcelona, Spain \\ ${ }^{3}$ Department of Pulmonary Diseases, GROW - School for Oncology \& Developmental Biology, Maastricht University Medical \\ Center+, Maastricht, The Netherlands \\ *Author for correspondence: Tel.: 0031043387 1318; Fax: 0031043387 5051; lizza.hendriks@mumc.nl
}

Immune checkpoint inhibitors (ICI) have revolutionized the treatment of many advanced cancers. However, in most pivotal trials, patients with brain metastases (BM) were either excluded, or only selected patients were allowed. Therefore, there are still some concerns about the safety/efficacy ratio of ICI in patients with BM. In this special report we will provide an overview on the biological rationale for using $\mathrm{ICl}$ in the treatment of BM, the reported BM-related outcomes of clinical trials with a focus on ICI plus chemotherapy and ICI plus ICl combinations. Last, we will provide future challenges with this strategy, as well as directions for future research.

First draft submitted: 22 February 2020; Accepted for publication: 1 May 2020; Published online: 15 May 2020

Keywords: brain/neurologic $\bullet$ clinical trials $\bullet$ immunotherapy $\bullet$ lung $\bullet$ melanoma $\bullet$ skin $\bullet$ urologic

The incidence of brain metastases $(\mathrm{BM})$ in cancer patients is high, especially in melanoma (7-60\%), lung (30$50 \%)$, breast (5-50\%) and renal cell cancer (RCC; 8\%) patients [1-10]. Quality of life (QoL) and overall survival (OS) are negatively influenced by the occurrence of BM [9,11]. Based on the longer OS of cancer patients, this incidence may increase over time. Therefore, treatment strategies for effectively treating (or even preventing) BM are eagerly awaited in daily clinical practice. Immune checkpoint inhibitors (ICI) have revolutionized the treatment landscape of many cancer types. PD-1/PD-L1 inhibitors with/without CTLA4 inhibitors or chemotherapy have become standard of care (SoC) in the first-line setting (and/or beyond) for many advanced solid tumors, such as non-small-cell lung cancer (NSCLC), small cell lung cancer (SCLC), BRAF wild-type melanoma and clear cell RCC (ccRCC) [12-16]. For several other histologies, ICI are still under evaluation in clinical trials.

Although ICI are widely being used across diverse tumor types, patients with untreated and/or symptomatic BM were either excluded from pivotal clinical trials or the percentage included was very low, with those patients enrolled being hyper-selected [17-27]. Therefore, there are still some concerns about the safety/efficacy ratio of ICI in patients with BM.

In this special report, we will provide an overview on the biological rationale for using ICI for treatment of BM and the reported BM related outcomes of clinical trials with a focus on ICI plus chemotherapy and ICI plus ICI combinations. Last, we will provide future challenges with this strategy, as well as directions for future research.

\section{Immune environment of brain metastases}

It was long thought that the brain was an immune privileged organ due to lack of traditional lymphatic structures. Recently, it has become clear that immune surveillance also takes place in the brain, as T-cells can cross the blood-brain barrier (BBB) and blood-tumor barrier [28,29]. However, in NSCLC, PD-L1 expression (a predictive biomarker for better outcome on anti-PD-[L]1 treatments), is lower in the brain than in extracranial metastases (30 vs 44\%) [30]. Furthermore, despite a higher tumor mutational burden (TMB) in NSCLC BM [31] as well as in ccRCC BM [32], the BM immune environment is more ignorant compared with extracranial disease sites [30,33,34].

Future Medicine 
Table 1. Tumor immune microenvironment in primary tumors and brain metastases matched samples.

\begin{tabular}{|c|c|c|c|c|c|}
\hline Study (year) & Samples & Sample type & Analysis & Main finding & Ref. \\
\hline $\begin{array}{l}\text { Cimino- } \\
\text { Mathews } \\
\text { et al. (2013) }\end{array}$ & $\mathrm{n}=6(\mathrm{PT})+6(\mathrm{BM})$ & FFPE & TMA & $\begin{array}{l}\text { BM contained fewer TIL compared with extra } \\
\text { cranial metastatic sites for lung, } \\
\text { gastrointestinal or gynecologic sites }\end{array}$ & [37] \\
\hline \multicolumn{6}{|l|}{ Breast cancer } \\
\hline $\begin{array}{l}\text { Ogiya } \\
\text { et al. (2017) }\end{array}$ & $\mathrm{n}=46(\mathrm{PT})+46(\mathrm{BM})$ & FFPE & TIL, IHC & $\begin{array}{l}\text { The numbers of } \mathrm{CD} 4 / \mathrm{CD} 8 / \text { Foxp3-positive cells } \\
\text { were significantly higher in breast PT } \\
\text { compared with } \mathrm{BM} \text { (paired } t \text {-test, } \mathrm{p}<0.05 \text { ). In } \\
\text { triple-negative breast cancer patients, low TILs } \\
\text { was associated with shorter overall survival } \\
\text { (log-rank test, } \mathrm{p}=0.04 \text { ) }\end{array}$ & [38] \\
\hline $\begin{array}{l}\text { Sobottka } \\
\text { et al. (2016) }\end{array}$ & $\mathrm{n}=87(\mathrm{PT})+87(\mathrm{BM})$ & FFPE & TIL (iTIL, sTIL, imTIL), IHC & $\begin{array}{l}\text { There were fewer TIL in BM than in PT } \\
(p<0.001) \text { but within the tumor } \\
\text { compartments, imTIL were more frequent than } \\
\text { sTIL and iTIL both within BM and the matched } \\
\text { breast PT }(p<0.001)\end{array}$ & [39] \\
\hline \multicolumn{6}{|l|}{ Melanoma } \\
\hline $\begin{array}{l}\text { Kluger } \\
\text { et al. (2015) }\end{array}$ & $\begin{array}{l}\mathrm{n}=95(\mathrm{ExM} \text { and } \\
\mathrm{PT})+5(\mathrm{BM})\end{array}$ & FFPE & TMA & $\begin{array}{l}\text { Although not significant, PD-L1 expression was } \\
\text { lower in BM compared with other sites. BM } \\
\text { displayed lower T-cell infiltration }(p<0.01)\end{array}$ & [40] \\
\hline \multicolumn{6}{|c|}{ Renal cell carcinoma } \\
\hline $\begin{array}{l}\text { Steindl } \\
\text { et al. (2019) }\end{array}$ & $\begin{array}{l}\mathrm{n}=6(\mathrm{PT})+4 \\
(\mathrm{ExM} \text { (lung)) }+10(\mathrm{BM})\end{array}$ & $\begin{array}{l}\text { FFPE and frozen } \\
\text { samples }\end{array}$ & TMB, TIL & $\begin{array}{l}\text { TMB and TIL were higher in BM than in } \\
\text { matched samples, although not statistically } \\
\text { significant }\end{array}$ & [32] \\
\hline Zhou et al. & $\mathrm{n}=25(\mathrm{PT})+25(\mathrm{BM})$ & FFPE & PD-L1, TIL & $\begin{array}{l}\text { CD8 }{ }^{+} \text {TILs were significantly fewer in BM than } \\
\text { in PT. Low stromal CD8 }{ }^{+} \text {TILs numbers in BMs } \\
\text { were associated with shorter OS }\end{array}$ & [41] \\
\hline \multicolumn{6}{|l|}{ NSCLC } \\
\hline $\begin{array}{l}\text { Mansfield et al., } \\
2016\end{array}$ & $\mathrm{n}=73(\mathrm{PT})+73(\mathrm{BM})$ & FFPE & PD-L1, TIL & $\begin{array}{l}\text { Discordance on tumor cells' PD-L1 and TILs' } \\
\text { PD-L1 between BM and PT was observed in } 14 \\
\text { and } 19 \% \text {, respectively }\end{array}$ & [30] \\
\hline $\begin{array}{l}\text { Mansfield } \\
\text { et al. (2018) }\end{array}$ & $\mathrm{n}=20(\mathrm{PT})+20(\mathrm{BM})$ & FFPE & $\begin{array}{l}\text { TCR- } \beta \text { sequencing, WES for TMB } \\
\text { assessment and neoantigens } \\
\text { detection }\end{array}$ & $\begin{array}{l}\text { BMs displayed a higher TMB, contained fewer } \\
\text { T-cell clones than PT matched samples. Most of } \\
\text { the T-cell clones differed between BM and PT }\end{array}$ & [33] \\
\hline Kudo et al., 2019 & $\mathrm{n}=39(\mathrm{PT})+39(\mathrm{BM})$ & FFPE & $\begin{array}{l}770 \text { genes expression panel, } \\
\text { TCR- } \beta \text { sequencing, IHC }\end{array}$ & $\begin{array}{l}\text { Hotspot mutations were mostly shared } \\
\text { between PT and BM }(71 \%) .161 \text { genes were } \\
\text { differentially expressed between PT and BM, } \\
\text { including downregulation of immune } \\
\text { pathways, } p<0.01 \text {. T-cell and macrophages } \\
\text { infiltration was reduced in BM compared with } \\
\text { PT }(p<0.001)\end{array}$ & [34] \\
\hline
\end{tabular}

BM: Brain metastasis; ExM: Extracranial metastasis; FFPE: Formalin-fixed paraffin-embedded; IHC: Immunohistochemistry; imTIL: invasive-margin lymphocyte; iTIL: intratumoral lymphocytes; PT: Primary tumor; sTIL: Stromal lymphocyte; TMA: Tissue microarray; TMB: Tumor mutational burden; TCR- $\beta$ : T-cell receptor- $\beta$; TIL: Tumor infiltrating lymphocyte; WES: Whole exome sequencing.

This spatial tumor microenvironment differences between primary and metastatic sites may explain heterogeneous responses rates on ICI.

Increasing data suggest that the brain micro-environment is immunosuppressive by itself [35], and may therefore promote BM development in various tumor histologies [36] as well as hamper anti-tumor immune response compared with other organ microenvironments (Table 1) [30,32-34,37-41]. Therefore, monotherapy strategies with ICI might be impaired and combination strategies could be more suitable/appropriate. All completed trials are summarized in Table 2 and are described in more detail below.

\section{ICl in monotherapy: data from clinical trials}

Despite a more immune ignorant phenotype in BM, for NSCLC, intracranial objective response rates (icORR) mirror extracranial ORR (ecORR). For example, in the single arm phase II trial (NCT02085070) evaluating pembrolizumab in melanoma or NSCLC patients with untreated BM (asymptomatic, maximum diameter 20 $\mathrm{mm}$ ), the updated results on 37 PD-L1-positive NSCLC patients showed an icORR of 29.7\% [47]. Similar results were found in a retrospective series: icORR was 27\% in 73 NSCLC with active BM [39]. Interestingly, in 13-21\% a dissociated response was described (response in brain and extracranial progression or vice versa) [47,48]. Except the 


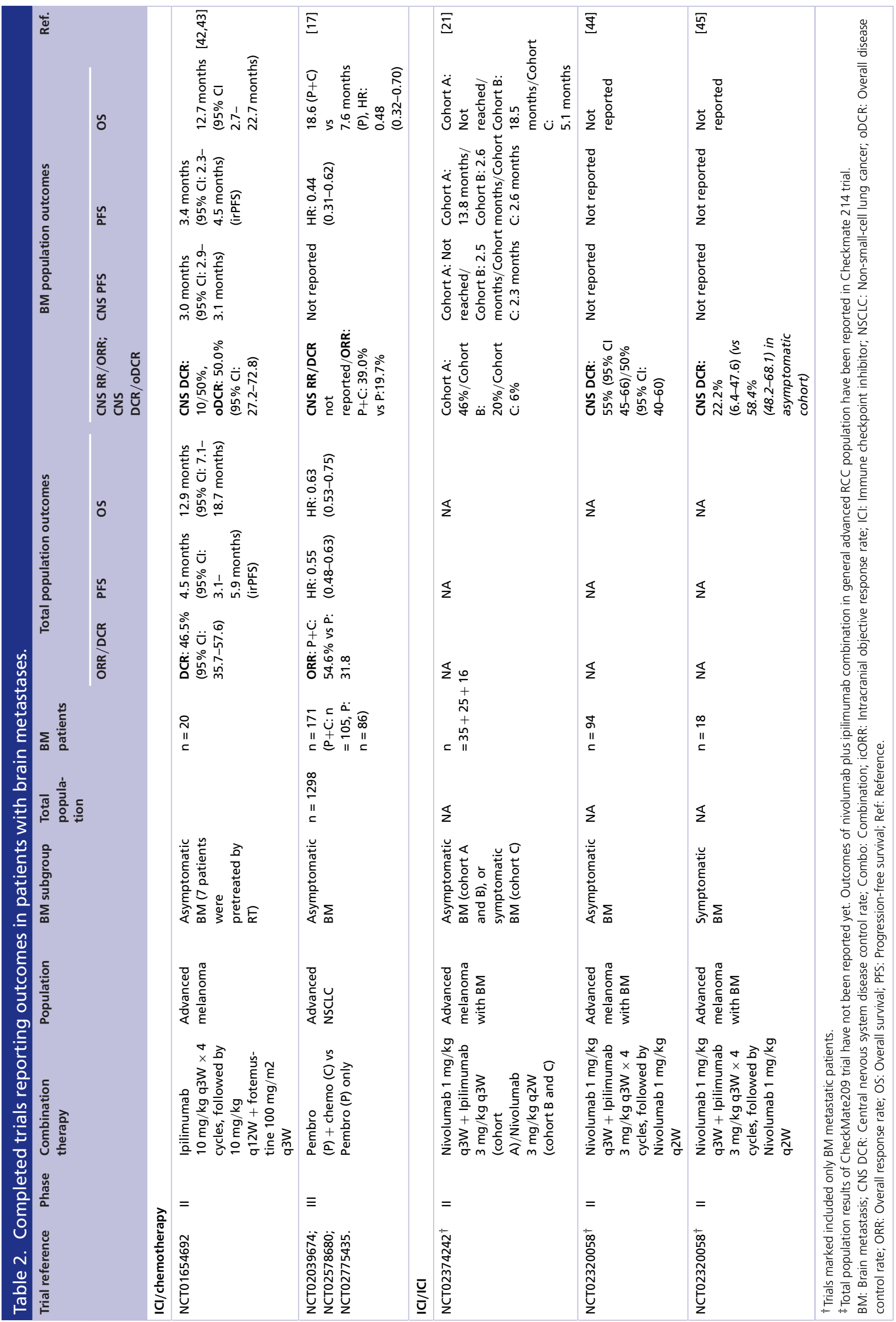




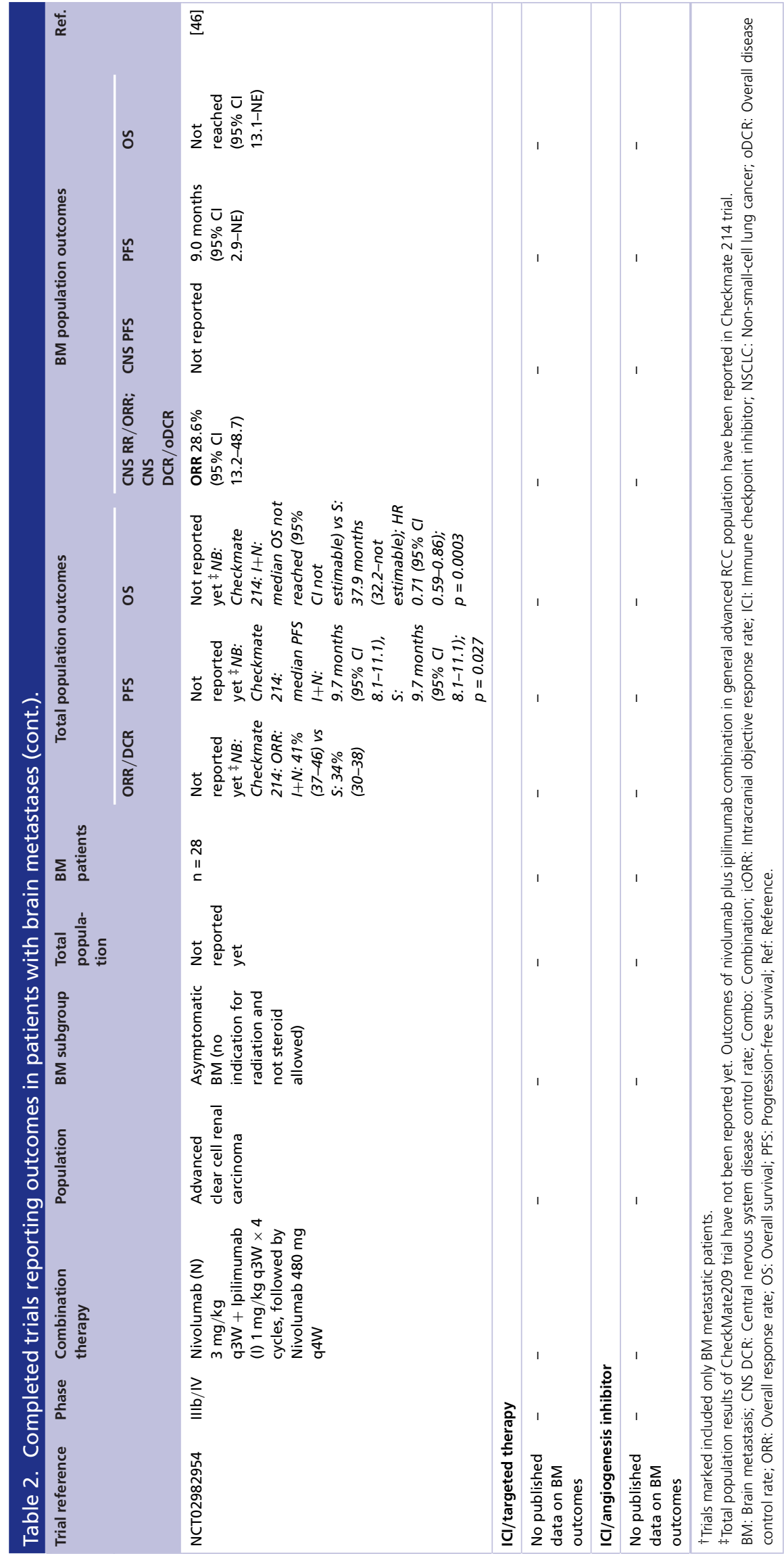


single arm phase II trial mentioned above, no lung cancer trials specifically focusing on ICI efficacy in BM patients have been reported yet. However, data have been reported regarding NSCLC BM patients treated within clinical trials. The largest clinical trial report comes from a pooled analysis $(n=3170$, of which 292 PD-L1 positive patients with BM) of four KEYNOTE studies (001, 010, 024 and 42). In the BM subgroup, median OS was longer with pembrolizumab compared with chemotherapy (13.2 vs 10.3 months), with a hazard ratio (HR) of 0.83 (95\% CI: 0.62-1.10). $159 \mathrm{BM}$ patients had a PD-L1 $\geq 50 \%$; and the HR for OS was 0.78 (95\% 0.71-0.85) [18]. However, stratification for $\mathrm{BM}$ was not performed.

In advanced/metastatic melanoma, the first data with ICI in patients with BM come from ipilimumab, although only radiotherapy pretreated BM patients were included. In a retrospective cohort study, ipilimumab showed equivalent efficacy in pretreated BM versus non-BM patients [49], questioning whether the benefit of ICI in $\mathrm{BM}$ is linked to the drug or previous radiotherapy. A phase II study evaluated ipilimumab in asymptomatic and symptomatic BM patients who had at least one measurable index BM (diameter 5-30 $\mathrm{mm}$ ), and/or two measurable $\mathrm{BM}>30 \mathrm{~mm}$ on baseline MRI [50]. In this study, patients could have been pretreated by whole-brain or stereotactic radiation (WBRT/SRT), but the index BM should either have been excluded from radiation fields or be progressive after any radiation. Ipilimumab achieved the highest disease control rate (DCR) in asymptomatic BM patients $(12 / 51,24 \%$, range (12-38)) compared with those with symptomatic BM on a stable dose of corticosteroids (2/21, $10 \%$ [range $1-30 \%]$ ] [50].

In the precited NCT02085070 phase II trial evaluating pembrolizumab in melanoma and NSCLC asymptomatic untreated BM patients, pembrolizumab monotherapy resulted in melanoma in an icORR of $22 \%$ (95\% CI: 7$48 \%$ [51]. Long-term update analysis was in line with this finding with an icORR of $26 \%$ and evidence of sustained clinical benefit with a 24 -month OS of $48 \%$ [52].

In advanced/metastatic ccRCC, nivolumab monotherapy resulted in a low icORR in a phase II study (12\% in 39 patients with previously untreated BM, $0 \%$ in the subgroup with multiple BM or BM larger than $1 \mathrm{~cm}$ ). The 1-year OS was $67 \%$ in previously untreated BM patients and 59\% in patients with BM that underwent prior therapy [53]. On the contrary, ORR was $25 \%$ with nivolumab monotherapy in the randomized phase III CheckMate 025 study (nivolumab vs everolimus in pretreated ccRCC patients) [54] and 21\% with nivolumab in a 'real life cohort' of 729 pretreated ccRCC patients (81 baseline BM, 12.3\%), in the multicenter NIVOREN GETUG AFU 26 study [55].

\section{Combination $\mathrm{ICl} / \mathrm{ICl}$ trial data}

\section{Rationale}

The synergistic effects of the combination of PD-(L) 1 and CTLA4 inhibitors are supported by preclinical studies, as monotherapy ICI might increase compensatory alternative immune checkpoints, and combination therapies increase T-cell infiltration and reduce regulatory T-cells [56].

For NSCLC, ICI/ICI combination data in BM patients are scarce. In the CheckMate 22 trial (nivolumab plus ipilimumab vs platinum-based chemotherapy) patients with treated BM were eligible, but outcomes of this subgroup have not been reported [57]. One cohort of the CheckMate 817 trial (first line nivolumab plus ipilimumab) included special populations (hepatic or renal impairment, HIV or untreated asymptomatic BM, with an ECOG PS of 0-1) [58]. Primary end point was toxicity. 50 out of the 198 included patients in the special population group had BM (25\%). BM-specific outcomes were not reported. $67 \%$ of patients had an adverse event, of which $28 \%$ was grade 3-4. Median progression free survival (PFS) was 3.9 months (95\% CI: 2.8-5.4), 1-year PFS was 26\% and median OS was 9.9 months (95\% CI: 7.0-13.7). Median duration of response (DoR) was 13.8 months (9.6-not reached), with 1-year DoR of $57 \%$ [58].

In melanoma, nivolumab/ipilimumab is superior to nivolumab alone. Data also support the use of this combination in BM patients.

The Checkmate 204 trial [44] evaluated four cycles of nivolumab plus ipilimumab, followed by nivolumab alone in $\mathrm{BM}$ patients with $\geq 1$ measurable and nonirradiated $\mathrm{BM}$ measuring $0.5-3.0 \mathrm{~cm}$. Patients were divided into two cohorts according to their neurological symptoms. Cohort $\mathrm{A}$ included patients with no neurological symptoms or steroids ( $\mathrm{n}=101,94$ with median follow-up $\geq 6$ months) and cohort $\mathrm{B}$ included those with neurological symptoms, with or without steroids ( $n=20,18$ with median follow-up $\geq 6$ months). Median follow-up was 14 months. In cohort A, the intraCNS clinical benefit (percentage of patients with stable disease [SD] $\geq 6$ months, partial or complete response [PR/CR]) was 57\% (95\% CI: 47-68), which was comparable to the 56\% (95\% CI: 46-67) extraCNS clinical benefit. CR, PR, and SD $\geq 6$ months were observed in 26,30 and $2 \%$, respectively. $55 \%$ had grade 3-4 adverse events. In an updated analysis of this trial [45], intracranial benefit rate was $>50 \%$ reduced in 
cohort B versus cohort A: 22.2\% (6.4-47.6) versus 58.4\% (48.2-68.1), respectively. Another Phase II trial [59] compared nivolumab versus nivolumab/ipilimumab. Asymptomatic, nonirradiated BM patients were randomized in two cohorts: nivolumab alone ( $A, n=36)$, or nivolumab/ipilimumab $(B, n=27)$. Cohort $C(n=16)$ enrolled patients with symptomatic or recurrent $\mathrm{BM}$ after local treatment, or leptomeningeal disease and was treated by nivolumab monotherapy. IcORR was $46 \%$ in cohort A (95\% CI: $29-63$ ), $20 \%$ in cohort B (95\% CI: 7-41), and $6 \%$ in cohort C (95\% CI: 0-30). Intracranial CR were observed in 17\%, 12\% and none, in cohort A, B and C, respectively.

In conclusion, limited data (only cohort B of Checkmate 204 trial) exist concerning the use of ICI combinations as the sole induction treatment for symptomatic previously untreated melanoma BM, and these patients often require multidisciplinary approach [60].

In advanced RCC patients with BM, nivolumab/ipilimumab results were reported in an interim analysis of the Checkmate 920 trial, a Phase IIIb/IV safety trial of nivolumab combined with ipilimumab in previously untreated advanced/metastatic RCC [46]. Although CNS icORR is not yet available and OS not reached, this combination was safe in BM patients, with an overall ORR of $28.6 \%$ (95\% CI: 13.2-48.7) and median PFS of 9.0 months (95\% CI: 2.9-NE). Comparatively, extended follow-up efficacy results of nivolumab/ipilimumab in treatment naive advanced or metastatic ccRCC have been reported in the pivotal phase III CheckMate 214 trial comparing ICI doublet with sunitinib: OS was not reached in the ICI combo arm, (95\% CI: 35.6-not estimable), median PFS was 8.2 months (95\% CI: 6.9-10.0) and ORR was $41 \%(37-46)$ in the intention to treat population [54,61].

\section{Combination $\mathrm{ICl} / \mathrm{chemo}$ data}

\section{Rationale}

It is currently well established that chemotherapy may increase ICI efficacy by increasing neoantigens release by inducing immunogenic cell death, increasing T-cell response and disrupting immune suppressive cells' activity [62].

Pembrolizumab/chemotherapy has become standard of care first line treatment for NSCLC regardless of PD-L1 expression and histologic subtype. In a pooled analysis of the KEYNOTE 021, 189 and 407 trials, 171 out of 1298 patients (13\%) had BM at baseline. In the KEYNOTE 189 and 407 trials, untreated, asymptomatic and small (maximum diameter $15 \mathrm{~mm}$ ) BM were allowed; however the percentage of these patients enrolled in both trials was not reported. Like the monotherapy trials, patients with BM also derived clinical benefit from the chemotherapy/pembrolizumab combination, as median OS was 18.8 months versus 7.6 months, with a HR of 0.48 (95\% CI: 0.32-0.70). Outcome of BM patients according to PD-L1 status was not reported. Percentage of neurological treatment related AEs (TRAEs) was similar, reaching approximately $30 \%$ in both arms [17].

For metastatic SCLC, ICI plus chemotherapy improved the OS compared with chemotherapy alone (IMpower133: atezolizumab plus chemotherapy [63], CASPIAN: durvalumab plus chemotherapy [13]). In the IMpower 133 study, 35/403 patients had baseline BM (9\%). In this small subgroup, the addition of atezolizumab did not result in an OS benefit (HR 1.07; 95\% CI: 0.47-2.43) [63]. In the CASPIAN trial there was a trend for an OS benefit in the small subgroup $(55 / 537,10 \%)$ of patients with baseline BM. HR for OS was 0.69 (95\% CI: $0.35-1.31)$ [13].

In melanoma, fotemustine combined with ipilimumab was evaluated in the NIBIT trial, which allowed inclusion of asymptomatic BM patients $(n=20 / 86)[42,43]$. IcORR was $40 \%$ with a median and CNS PFS of both 3 months and OS of 13.4 months. Three-year follow-up analysis revealed a median OS of 12.9 months (95\% CI: 7.1-18.7) for the whole study population, and 12.7 months (95\% CI: 2.7-22.7) for the BM subpopulation.

\section{Combination ICl-targeted therapy \\ Rationale}

For melanoma, combination therapies of targeted therapy and ICI are supported by robust preclinical data [64]. For example, it has been shown that MAPK inhibition may increase neoantigens, enhance function of immune cells (dendritic cells, T cells, NKs) and decrease the function of immunosuppressive cells (cancer associated fibroblasts, tumor associated macrophages) [65,66]. Data for lung cancer are lacking.

$\mathrm{ICI} /$ targeted therapy combinations that are under investigation for advanced/metastatic melanoma include $\mathrm{PD}(\mathrm{L})-1$ or CTLA4 inhibitors \pm BRAF and/or MEK inhibitors. Some of these trials allowed asymptomatic BM (e.g., NCT01673854 [67]) or treated/inactive BM (e.g., NCT02908672, NCT02130466, NCT02967692) but BM specific outcomes have not been reported. Besides, several trials are ongoing evaluating these combinations either in concurrent or sequential settings (NCT02631447, NCT02224781, NCT01940809, NCT03235245, 
NCT02902029, NCT02902042, NCT02967692, NCT02818023), but none of these trials allows active and/or nontreated BM patients.

Interestingly, the phase I/II trial NCT02910700 (nivolumab combined with trametinib with or without dabrafenib), was amended to allow the inclusion of patients with untreated BM. BM patients are divided into two cohorts according to their symptom or CNS progression status; recruitment is ongoing (Table 3).

\section{Combination ICl-radiotherapy for brain metastases}

\section{Rationale}

Radiotherapy increases immunogenicity [68] by release of cytokines, neoantigens and may promote BBB permeability as well as reduce peritumoral edema hence enabling to reduce steroid dosage. Cranial irradiation improves intracranial responses and disease control. Furthermore, radiation acts synergistically with ICI [69]. Therefore, it is of interest to combine these two treatment modalities. However, prospective trial data are lacking.

Based on retrospective series, the combination of anti-PD-[L]1 inhibition and ICI is safe, but the combination of anti-CTLA4 and ICI seems to increase the risk of radiation necrosis $[19,70]$. However, detailed neurotoxicity assessments for the combination treatment are not available. Based on the available retrospective data, concurrent ICI/radiotherapy results in an improved survival compared with sequential treatment strategies [19,70]. A drawback of these retrospective series is the bias for selecting patients for a certain treatment sequence. For example, those that are treated with cranial irradiation because of brain progression on ICI, obviously have a poorer survival than those that can be treated concurrently. Moreover, those that need to be treated with cranial irradiation before start of ICI because of symptoms, are probably another group of patients than those in the concurrent group.

A series of ongoing trials aim at evaluating the combination of radiotherapy plus ICI (Table 3).

\section{Combination ICl/angiogenesis inhibitors for brain metastases Rationale}

Angiogenesis inhibitors may normalize the vasculature and increase T-cell migration within the tumor bed, hence fostering ICI efficacy [71]. Moreover, adding an angiogenesis inhibitor to ICI may allow to reduce peritumoral edema for BM patients, enabling the reduction of steroid dosage.

For metastatic NSCLC, the combination of atezolizumab plus bevacizumab and carboplatin/paclitaxel is the other approved first-line chemotherapy/ICI regimen based on the phase III IMpower150 trial, however BM specific outcomes have not been reported in this trial [72]. This is unfortunate, as in the phase II BRAIN trial, the addition of bevacizumab to chemotherapy has reported an icORR of $61 \%$ in NSCLC patients with asymptomatic and untreated BM. Indeed, there is a rationale for the synergism between antiangiogenic treatment and ICI. Furthermore bevacizumab may overcome radionecrosis [72-74].

In ccRCC, the combination of ICI and VEGF targeting therapies has shown promising efficacy [75-77] leading to FDA+EMA approval of pembrolizumab plus axitinib and avelumab plus axitinib in first line in advanced settings. Patients with BM were allowed in the pembrolizumab/axitinib trial (KEYNOTE-426) if asymptomatic, but data for this subgroup is not yet available. Similarly, the IMmotion 151 trial (atezolizumab/bevacizumab vs sunitib) included only patients with treated BM and data of this subgroup is not available.

\section{Future perspective}

As outcome of patients with BM is still often poor, efforts should be put in improving treatment as well as selection for treatment. Possible options are:

\section{Alternative $\mathrm{ICl}$ combinations}

Numerous other potential ICI combinations should also be tested in BM patients including IDO/CTLA4/PD(L)1, LAG-3/PD-(L1) inhibition [78]. Moreover, in advanced melanoma, combination of talimogene laherparepvec (T-VEC) with pembrolizumab is under evaluation to study its ability to revert pembrolizumab resistance [79] (NCT02965716). Regarding BM, only those with treated BM are eligible in this study. One report of CR of T$\mathrm{Vec} /$ pembrolizumab associated with WBRT confirms that this association is feasible and might be envisioned after failure of ICI/ICI combination therapy in BM patients [80]. Furthermore, TKI combined with ICI is an interesting option, especially in melanoma. Future trials should also include subgroups of BM patients. Last, combinations of ICI and epigenetic targeting therapy or DNA repair targeting agents are currently under investigation and might bring benefit as well for BM patients. 


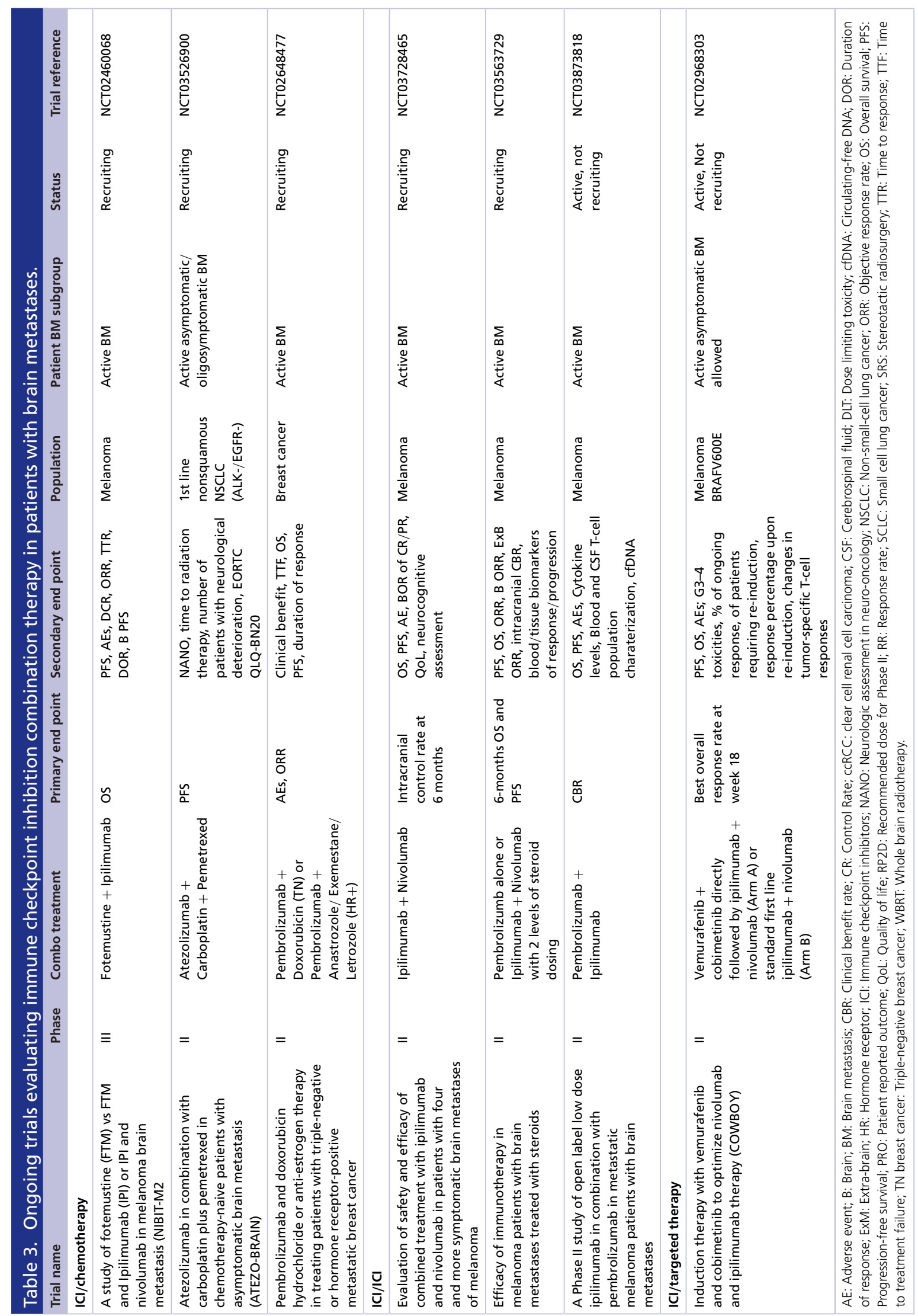




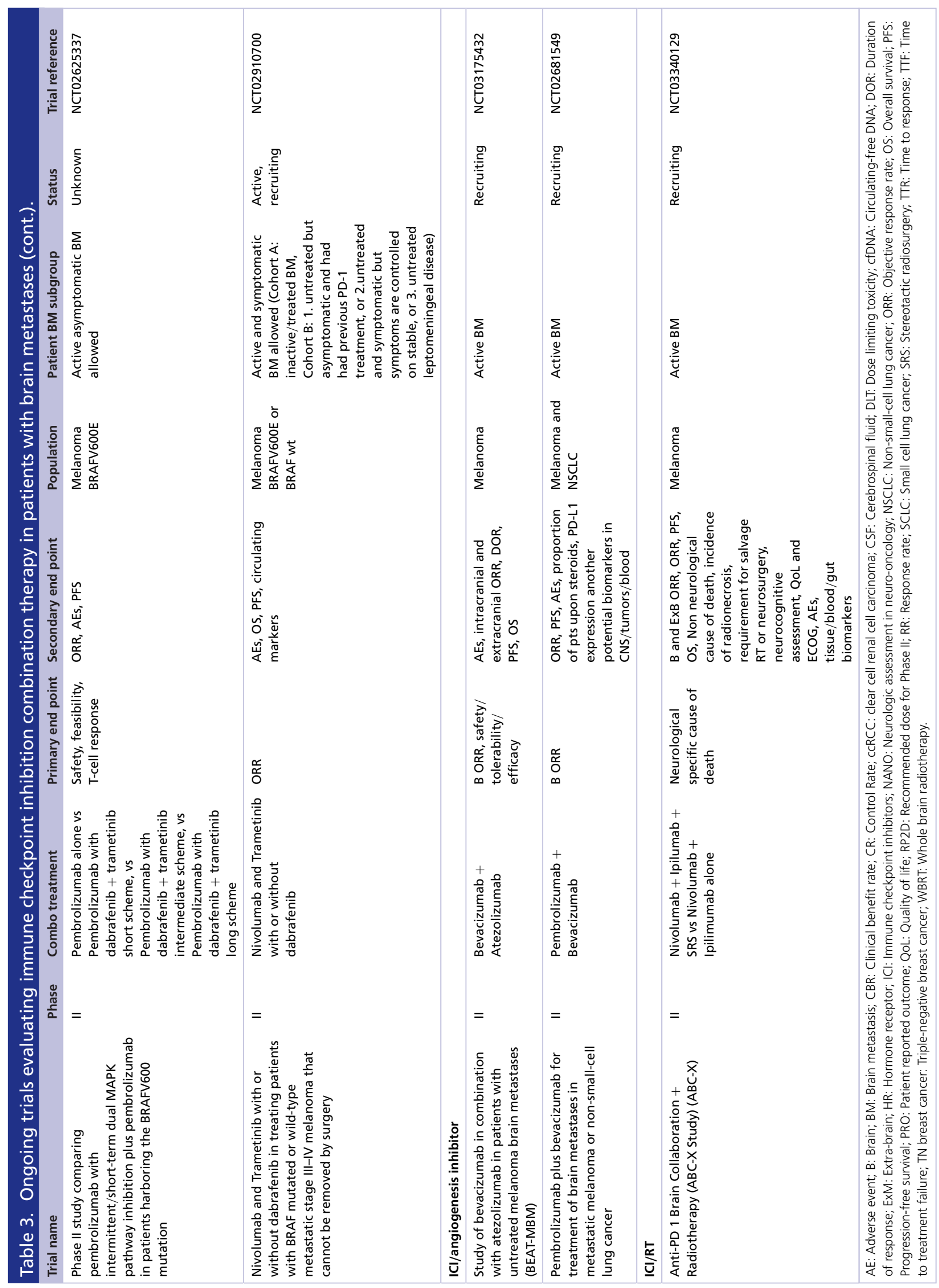




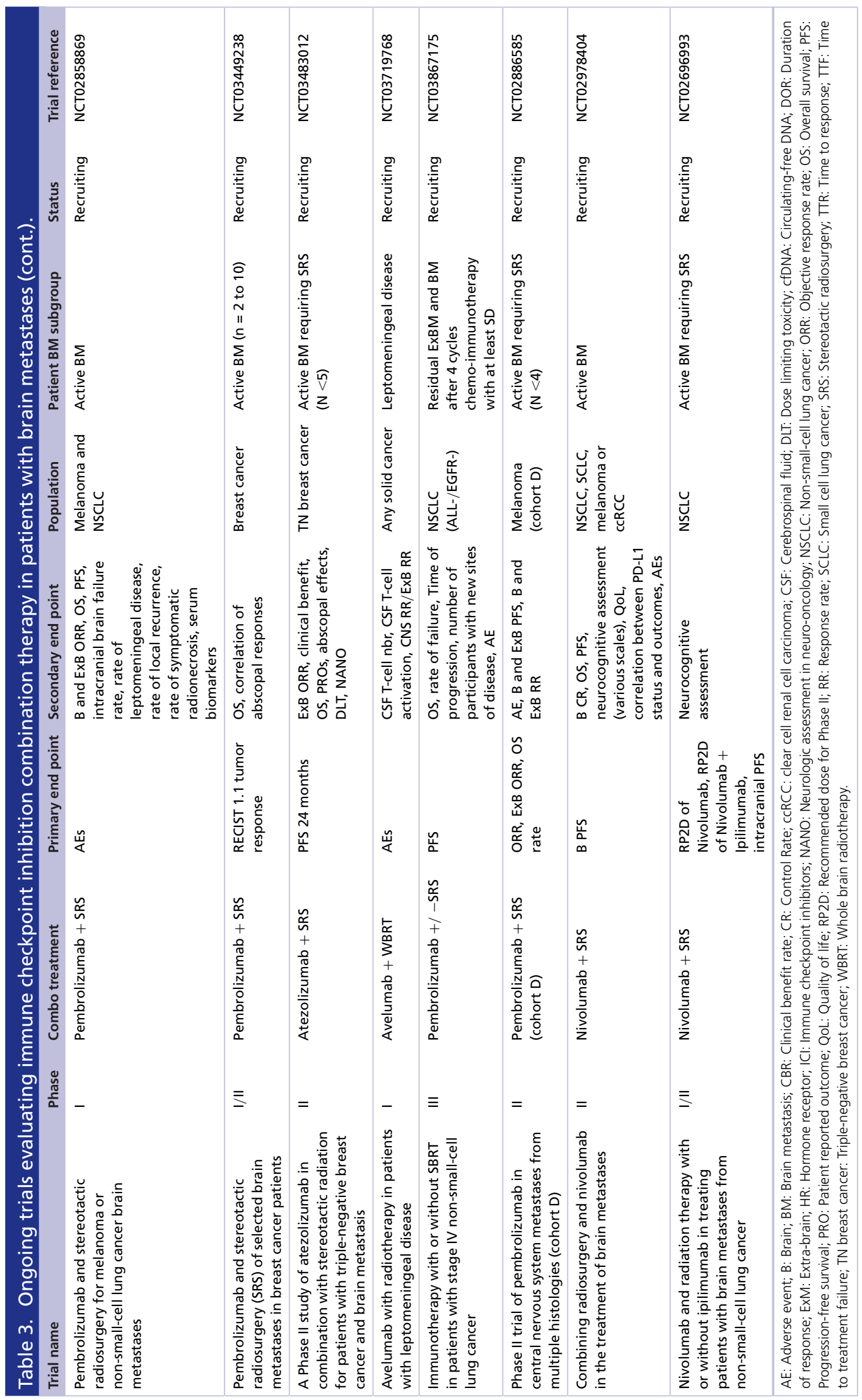




\section{Predictive biomarkers \& prognostic scores}

ICI, especially ICI combination therapy data for BM patients is still limited, and data available cannot be extrapolated to daily clinical practice as patients included in clinical trials were usually very selected (good performance, no or only low dose corticosteroids, small, asymptomatic and often locally pretreated BM). Furthermore, predictive markers for BM response are not well known.

Therefore, trials should incorporate BM-specific end points, as was recommended by a recent Response Assessment in Neuro-Oncology (RANO) working group statement. They state that if there is a signal for intracranial efficacy (as is the case for ICI combinations), clinical trials should have bicompartmental response assessments (separate cranial and extracranial end points) [81]. Moreover, predictive factors and biomarkers should be evaluated prospectively, also in ICI combination treated patients. For example, in a retrospective series, disease-specific Graded Prognostic Assessment (ds-GPA) was associated with survival in monotherapy ICI treated NSCLC patients [48]. In the pooled analysis of the monotherapy pembrolizumab NSCLC trials, those with PD-L1 $\geq 50 \%$ had the best outcome [18] but it is not clear whether these results can be translated to patients treated with ICI combinations.

\section{Response assessment end points}

Furthermore, it is known that with ICI treatment, dissociated responses can occur [47,48]. The RANO working group advises to incorporate in the clinical trial protocols the actions that are allowed in case progression occurs in one compartment (e.g., SRT for a growing BM, with the continuation of the ICI, as the extracranial disease is under control) [81] Intracranial response assessments can be challenging, as pseudoprogression can occur with ICI [82] and radiation necrosis (with as a result a growing BM) can occur especially after SRT [73]. The RANO group has published specific criteria for response assessment in BM patients (depending on clinical condition and time since initiation of ICI: discontinue ICI or continue ICI with follow-up brain imaging) [83], but these criteria should be prospectively validated. Furthermore, it is not clear whether these criteria also apply for ICI/chemotherapy treated patients as the rate of pseudoprogression is probably lower in this patient population. New imaging techniques such as perfusion-weighted magnetic resonance imaging (PWI) and diffusion-weighted magnetic resonance imaging (DWI) are promising tools to differentiate pseudoprogression/radiation necrosis from real progression, and should be prospectively evaluated, as are several positron emission tomography tracers such as 18F-fluoroethyl-L-tyrosine, 18-F-fluorothymidine and 11C-methyl-L-methionine [84]. Alternate contrast agents may also address this question, as exemplified by NCT03325166 which currently evaluates a new contrast agent (ferumoxytol) to differentiate pseudoprogression and real progression.

Last, attention should be paid to long-term neurotoxicity of ICI. Severe neurotoxicity is rare in ICI treated patients [85] but data regarding low-grade toxicity are lacking.

\section{Conclusion}

ICI, especially ICI combinations are promising treatments strategies for patients with BM, but factors associated with response and survival should be prospectively evaluated. Furthermore, the optimal treatment sequence (upfront systemic treatment vs upfront SRT followed by systemic treatment) should be defined, as well as the potential deleterious effect of steroids at baseline. New imaging techniques could be helpful for differentiating between pseudoprogression and real progression. As delayed neurotoxicity remains unknown, improving survival with maintaining QoL is mandatory in a population who may achieve prolonged outcomes.

Financial \& competing interests disclosure

No authors have financial disclosures relating to the current manuscript. J Remon has advisory role for Boehringer-Ingelheim, MSD, Pfizer, BMS, Astra-Zeneca; and received travel reimbursement from OSE immunotherapeutics, BMS, Astra-Zeneca. L Hendriks has advisory role for Boehringer, BMS, Lilly, Roche, Pfizer, Takeda, MSD (all institution); received research funding from Roche, Boehringer Ingelheim, AstraZeneca (all institution); speaker for MSD; travel/conference reimbursement from Roche, BMS; mentorship program with key opinion leaders funded by AstraZeneca; fees for educational webinars funded by Quadia (self); interview sessions funded by Roche (institution). The authors have no other relevant affiliations or financial involvement with any organization or entity with a financial interest in or financial conflict with the subject matter or materials discussed in the manuscript apart from those disclosed.

No writing assistance was utilized in the production of this manuscript.

\section{References}

Papers of special note have been highlighted as: $\bullet$ of interest; $\bullet \bullet$ of considerable interest 
Executive summary

ICI in monotherapy: data from clinical trials

- Monotherapy ICI icORR mirrors ecORR.

Combination $\mathrm{ICl} / \mathrm{ICl}$ trial data

- Symptomatic BM patients seem to less benefit from ICl combinations compared with neurologically asymptomatic patients.

- $\mathrm{ICl} / \mathrm{ICl}$ combinations are effective in the treatment of melanoma BM. Other tumor types should be further evaluated.

Combination $\mathrm{ICl} /$ chemo data

- $\mathrm{ICl} / \mathrm{chemotherapy} \mathrm{combinations} \mathrm{are} \mathrm{effective} \mathrm{in} \mathrm{the} \mathrm{treatment} \mathrm{of} \mathrm{NSCLC} \mathrm{BM.}$

Combination ICl-radiotherapy for brain metastases

- $\mathrm{ICl} /$ radiotherapy combinations are being tested in clinical trials, the optimal sequence needs to be defined.

Future perspective

- With prolonged survival, long-term toxicity becomes more and more important and should be evaluated.

1. Bedikian AY, Wei C, Detry M et al. Predictive factors for the development of brain metastasis in advanced unresectable metastatic melanoma. Am. J. Clin. Oncol. 34(6), 603-610 (2011).

2. Ajithkumar T, Parkinson C, Fife K, Corrie P, Jefferies S. Evolving treatment options for melanoma brain metastases. Lancet Oncol. 16(13), e486-497 (2015).

3. Nayak L, Lee EQ, Wen PY. Epidemiology of brain metastases. Curr. Oncol. Rep. 14(1), 48-54 (2012).

4. DeAngelis LM, Posner JB. Neurologic Complications of Cancer. 2nd Edition. Oxford University Press, Oxford, NY, USA

5. Leone JP, Leone BA. Breast cancer brain metastases: the last frontier. Exp. Hematol. Oncol. 4, 33 (2015).

6. Leone JP, Leone J, Zwenger AO, Iturbe J, Leone BA, Vallejo CT. Prognostic factors and survival according to tumour subtype in women presenting with breast cancer brain metastases at initial diagnosis. Eur. J. Cancer Oxf. Engl. 1990. 74, 17-25 (2017).

7. Lin NU, Amiri-Kordestani L, Palmieri D, Liewehr DJ, Steeg PS. CNS metastases in breast cancer: old challenge, new frontiers. Clin. Cancer Res. Off. J. Am. Assoc. Cancer Res. 19(23), 6404-6418 (2013).

8. Berghoff AS, Schur S, Füreder LM et al. Descriptive statistical analysis of a real life cohort of 2419 patients with brain metastases of solid cancers. ESMO Open. 1(2), e000024 (2016).

9. Achrol AS, Rennert RC, Anders C et al. Brain metastases. Nat. Rev. Dis. Primer. 5(1), 5 (2019).

10. Sun M, De Velasco G, Brastianos PK et al. The development of brain metastases in patients with renal cell carcinoma: epidemiologic trends, survival, and clinical risk factors using a population-based cohort. Eur. Urol. Focus 5(3), 474-481 (2019).

11. Peters S, Bexelius C, Munk V, Leighl N. The impact of brain metastasis on quality of life, resource utilization and survival in patients with non-small-cell lung cancer. Cancer Treat. Rev. 45, 139-162 (2016).

12. Planchard D, Popat S, Kerr K et al. Metastatic non-small-cell lung cancer: ESMO Clinical Practice Guidelines for diagnosis, treatment and follow-up. Ann. Oncol. Off. J. Eur. Soc. Med. Oncol. 29(Suppl. 4), iv192-iv237 (2018).

13. Paz-Ares L, Dvorkin M, Chen Y et al. Durvalumab plus platinum-etoposide versus platinum-etoposide in first-line treatment of extensive-stage small-cell lung cancer (CASPIAN): a randomised, controlled, open-label, phase 3 trial. Lancet Lond. Engl. 394(10212), 1929-1939 (2019).

14. Horn L, Mansfield AS, Szczęsna A et al. First-line atezolizumab plus chemotherapy in extensive-stage small-cell lung cancer. $N$. Engl. J. Med. 379(23), 2220-2229 (2018).

15. Michielin O, van Akkooi ACJ, Ascierto PA, Dummer R, Keilholz U. . Cutaneous melanoma: ESMO Clinical Practice Guidelines for diagnosis, treatment and follow-up. Ann. Oncol. Off. J. Eur. Soc. Med. Oncol. 30(12), 1884-1901 (2019).

16. Escudier B, Porta C, Schmidinger M et al. Renal cell carcinoma: ESMO Clinical Practice Guidelines for diagnosis, treatment and follow-up. Ann. Oncol. Off. J. Eur. Soc. Med. Oncol. 30(5), 706-720 (2019).

17. Powell SF, Rodriguez-Abreu D, Langer C et al. Pembrolizumab plus platinum based chemotherapy in NSCLC with brain metastases: pooled analysis of KEYNOTE 021, 189, and 407. Ann. Oncol. 30, v602-v660 (2019).

- This is the first trial data reporting on ICI-chemotherapy efficacy in NSCLC patients with brain metastases.

18. Mansfield A, Herbst R, Castro G et al. Outcomes with pembrolizumab monotherapy in patients with PD L1 positive NSCLC with brain metastases: pooled analysis of KEYNOTE 001, 010, 024, and 042. Ann. Oncol. 30, v602-v660 (2019).

19. El Rassy E, Botticella A, Kattan J, Le Péchoux C, Besse B, Hendriks L. non-small-cell lung cancer brain metastases and the immune system: from brain metastases development to treatment. Cancer Treat. Rev. 68, 69-79 (2018).

20. Robert C, Schachter J, Long GV et al. Pembrolizumab versus ipilimumab in advanced melanoma. N. Engl. J. Med. 372(26), 2521-2532 (2015). 
21. Long GV, Atkinson V, Cebon JS et al. Standard-dose pembrolizumab in combination with reduced-dose ipilimumab for patients with advanced melanoma (KEYNOTE-029): an open-label, phase 1b trial. Lancet Oncol. 18(9), 1202-1210 (2017).

22. Larkin J, Chiarion-Sileni V, Gonzalez R et al. Combined nivolumab and ipilimumab or monotherapy in untreated melanoma. N. Engl. J. Med. 373(1), 23-34 (2015).

23. Wolchok JD, Kluger H, Callahan MK et al. Nivolumab plus ipilimumab in advanced melanoma. N. Engl. J. Med. 369(2), 122-133 (2013).

24. Wolchok JD, Chiarion-Sileni V, Gonzalez R et al. Overall survival with combined nivolumab and ipilimumab in advanced melanoma. N. Engl. J. Med. 377(14), 1345-1356 (2017).

25. Larkin J, Chiarion-Selini V, Gonzalez R et al. Five-year survival with combined nivolumab and ipilimumab in advanced melanoma. $N$. Engl. J. Med 381(16), 1535-1546 (2019).

26. Tykodi SS, Donskov F, Lee JL et al. First-line pembrolizumab (pembro) monotherapy in advanced clear cell renal cell carcinoma (ccRCC): updated results for KEYNOTE-427 cohort A. J. Clin. Oncol. 37(Suppl. 15), 4570-4570 (2019).

27. McDermott DF, Lee JL, Ziobro $\mathrm{M}$ et al. First-line pembrolizumab (pembro) monotherapy for advanced non-clear cell renal cell carcinoma (nccRCC): Results from KEYNOTE-427 cohort B. J. Clin. Oncol. 37(Suppl. 7), 546-546 (2019).

28. Ransohoff RM, Engelhardt B. The anatomical and cellular basis of immune surveillance in the central nervous system. Nat. Rev. Immunol. 12(9), 623-635 (2012).

29. Owens T, Renno T, Taupin V, Krakowski M. Inflammatory cytokines in the brain: does the CNS shape immune responses? Immunol. Today 15(12), 566-571 (1994).

30. Mansfield AS, Aubry MC, Moser JC et al. Temporal and spatial discordance of programmed cell death-ligand 1 expression and lymphocyte tumor infiltration between paired primary lesions and brain metastases in lung cancer. Ann. Oncol. Off. J. Eur. Soc. Med. Oncol. 27(10), 1953-1958 (2016).

- This is the first report evaluating PD-L1 expression differences between paired primary tumor and brain metastases in lung cancer.

31. Stein MK, Pandey M, Xiu J et al. Tumor mutational burden is site specific in non-small-cell lung cancer and is highest in lung adenocarcinoma brain metastases. JCO Precis. Oncol. (3), 1-13 (2019).

32. Steindl A, Bergen ES, Alpar D et al. 403PD - Tumour mutational burden and immune infiltrates in primary renal cell carcinoma and matched brain metastases. Ann. Oncol. 30, v148 (2019).

33. Mansfield AS, Ren H, Sutor S et al. Contraction of T cell richness in lung cancer brain metastases. Sci. Rep. 8(1), 1-9 (2018).

-. This is one of the first reports evaluating the immune enviroment of brain metastases.

34. Kudo Y, Haymaker C, Zhang J et al. Suppressed immune microenvironment and repertoire in brain metastases from patients with resected non-small-cell lung cancer. Ann. Oncol. Off. J. Eur. Soc. Med. Oncol. 30(9), 1521-1530 (2019).

35. Quail DF, Joyce JA. The microenvironmental landscape of brain tumors. Cancer Cell. 31(3), 326-341 (2017).

36. Leibold AT, Monaco GN, Dey M. The role of the immune system in brain metastasis. Curr. Neurobiol. 10(2), 33-48 (2019).

37. Cimino-Mathews A, Ye X, Meeker A, Argani P, Emens LA. Metastatic triple-negative breast cancers at first relapse have fewer tumor-infiltrating lymphocytes than their matched primary breast tumors: a pilot study. Hum. Pathol. 44(10), 2055-2063 (2013).

38. Ogiya R, Niikura N, Kumaki N et al. Comparison of immune microenvironments between primary tumors and brain metastases in patients with breast cancer. Oncotarget 8(61), 103671-103681 (2017).

- This is one of the first reports evaluating the immune environment in breast cancer brain metastases.

39. Sobottka B, Pestalozzi B, Fink D, Moch H, Varga Z. Similar lymphocytic infiltration pattern in primary breast cancer and their corresponding distant metastases. Oncoimmunology 5(6), e1153208 (2016).

40. Kluger HM, Zito CR, Barr ML et al. Characterization of PD-L1 expression and associated T-cell infiltrates in metastatic melanoma samples from variable anatomic sites. Clin. Cancer Res. Off. J. Am. Assoc. Cancer Res. 21(13), 3052-3060 (2015).

41. Zhou J, Gong Z, Jia Q, Wu Y, Yang Z-Z, Zhu B. Programmed death ligand 1 expression and CD8+ tumor-infiltrating lymphocyte density differences between paired primary and brain metastatic lesions in non-small-cell lung cancer. Biochem. Biophys. Res. Commun. 498(4), 751-757 (2018).

42. Di Giacomo AM, Ascierto PA, Pilla L et al. Ipilimumab and fotemustine in patients with advanced melanoma (NIBIT-M1): an open-label, single-arm phase 2 trial. Lancet Oncol. 13(9), 879-886 (2012).

43. Di Giacomo AM, Ascierto PA, Queirolo P et al. Three-year follow-up of advanced melanoma patients who received ipilimumab plus fotemustine in the Italian Network for Tumor Biotherapy (NIBIT)-M1 Phase II study. Ann. Oncol. Off. J. Eur. Soc. Med. Oncol. 26(4), 798-803 (2015).

44. Tawbi HA, Forsyth PA, Algazi A et al. Combined nivolumab and ipilimumab in melanoma metastatic to the brain. N. Engl. J. Med. 379(8), 722-730 (2018). 
45. Tawbi H, Forsyth P, Hodi F et al. Efficacy and safety of the combination of nivolumab (NIVO) plus ipilimumab (IPI) in patients with symptomatic melanoma brain metastases (CheckMate 204). J. Clin.

Oncol. (2019) https://ascopubs.org/doi/abs/10.1200/JCO.2019.37.15_suppl.9501

•• The first trial evaluating ICI in patients with symptomatic brain metastases.

46. Emamekhoo H, Olsen M, Carthon BC et al. Safety and efficacy of nivolumab plus ipilimumab (NIVO+IPI) in patients with advanced renal cell carcinoma (aRCC) with brain metastases: Interim analysis of CheckMate 920. J. Clin. Oncol. 37(Suppl. 15), 4517-4517 (2019).

-. The first trial evaluating ICI-ICI in RCC brain metastases.

47. Goldberg SB, Schalpei KA, Gettinger SN et al. Pembrolizumab for management of patients with NSCLC and brain metastases: long-term results and biomarker analysis from a non-randomised, open-label, Phase II trial. Lancet Oncol. (2020) epub ahead of print. doi:10.1016/S1470-2045(20)30111-X

48. Hendriks LEL, Henon C, Auclin E et al. Outcome of non-small-cell lung cancer patients with brain metastases treated with checkpoint inhibitors. J. Thorac. Oncol. Off. Publ. Int. Assoc. Study Lung Cancer 14(7), 1244-1254 (2019).

49. Tazi K, Hathaway A, Chiuzan C, Shirai K. Survival of melanoma patients with brain metastases treated with ipilimumab and stereotactic radiosurgery. Cancer Med. 4(1), 1-6 (2015).

50. Margolin K, Ernstoff MS, Hamid O et al. Ipilimumab in patients with melanoma and brain metastases: an open-label, phase 2 trial. Lancet Oncol. 13(5), 459-465 (2012).

-. This is the first report of ipilimumab efficacy in brain metastses from melanoma.

51. Goldberg SB, Gettinger SN, Mahajan A et al. Pembrolizumab for patients with melanoma or non-small-cell lung cancer and untreated brain metastases: early analysis of a non-randomised, open-label, Phase II trial. Lancet Oncol. 17(7), 976-983 (2016).

-. This is the first Phase II trial evaluating pembrolizumab in NSCLC and melanoma brain metastases patients.

52. Kluger HM, Chiang V, Mahajan A et al. Long-term survival of patients with melanoma with active brain metastases treated with pembrolizumab on a Phase II trial. J. Clin. Oncol. Off. J. Am. Soc. Clin. Oncol. 37(1), 52-60 (2019).

53. Flippot R, Dalban C, Laguerre B et al. Safety and efficacy of nivolumab in brain metastases from renal cell carcinoma: results of the GETUG-AFU 26 NIVOREN multicenter Phase II study. J. Clin. Oncol. Off. J. Am. Soc. Clin. Oncol. 37(23), 2008-2016 (2019).

54. Motzer RJ, Escudier B, McDermott DF et al. Nivolumab versus everolimus in advanced renal-cell carcinoma. N. Engl. J. Med. 373(19), 1803-1813 (2015).

55. Albiges L, Negrier S, Dalban C et al. Safety and efficacy of nivolumab in metastatic renal cell carcinoma (mRCC): final analysis from the NIVOREN GETUG AFU 26 study. J.Clin. Oncol. 37(Suppl. 7), 452 (2019).

56. Spranger S, Koblish HK, Horton B, Scherle PA, Newton R, Gajewski TF. Mechanism of tumor rejection with doublets of CTLA-4, PD-1/PD-L1, or IDO blockade involves restored IL-2 production and proliferation of CD8(+) T cells directly within the tumor microenvironment. J. Immunother. Cancer. 2, 3 (2014).

57. Hellmann MD, Ciuleanu T-E, Pluzanski A et al. Nivolumab plus ipilimumab in lung cancer with a high tumor mutational burden. $N$. Engl. J. Med. 378(22), 2093-2104 (2018).

58. Barlesi F, Audigier-Valette C, Felip E et al. OA04.02 CheckMate 817: first-line nivolumab + ipilimumab in patients with ECOG PS 2 and other special populations with advanced NSCLC. J. Thorac. Oncol. 14(10), S214-S215 (2019).

59. Long GV, Atkinson V, Lo $S$ et al. Combination nivolumab and ipilimumab or nivolumab alone in melanoma brain metastases: a multicentre randomised phase 2 study. Lancet Oncol. 19(5), 672-681 (2018).

-. The first trial evaluating an ICI-ICI strategy in melanoma brain metastases.

60. Qian JM, Yu JB, Mahajan A, Goldberg SB, Kluger HM, Chiang VLS. Frequent use of local therapy underscores need for multidisciplinary care in the management of patients with melanoma brain metastases treated with PD-1 inhibitors. Int. J. Radiat. Oncol. Biol. Phys. 105(5), 1113-1118 (2019).

61. Motzer RJ, Rini BI, McDermott DF et al. Nivolumab plus ipilimumab versus sunitinib in first-line treatment for advanced renal cell carcinoma: extended follow-up of efficacy and safety results from a randomised, controlled, phase 3 trial. Lancet Oncol. 20(10), $1370-1385$ (2019).

62. Emens LA, Middleton G. The interplay of immunotherapy and chemotherapy: harnessing potential synergies. Cancer Immunol. Res. 3(5), 436-443 (2015).

63. Mok TSK, Reck M, Horn L et al. IMpower133: primary efficacy and safety + CNS-related adverse events in a phase I/III study of first-line (1L) atezolizumab + carboplatin + etoposide in extensive-stage SCLC (ES-SCLC). Ann. Oncol. 29, ix173 (2018).

64. Yu C, Liu X, Yang J et al. Combination of immunotherapy with targeted therapy: theory and practice in metastatic melanoma. Front Immunol. 10, 990 (2019).

65. Callahan MK, Masters G, Pratilas CA et al. Paradoxical activation of T cells via augmented ERK signaling mediated by a RAF inhibitor. Cancer Immunol. Res. 2(1), (2014). 
66. Callahan M, Masters G, Katz J et al. The immunological impact of the RAF inhibitor BMS908662: preclinical and early clinical experience in combination with CTLA-4 blockade. J.Clin. Oncol. 30( Suppl. 15), 2521 (2012).

67. Amin A, Lawson DH, Salama AK et al. A single-arm, open-label, Phase II study to evaluate the safety of vemurafenib (VEM) followed by ipilimumab (IPI) in BRAF V600-mutated metastatic melanoma (MM). J. Clin. Oncol. 33(Suppl. 15), 9032-9032 (2015).

68. Spaas M, Lievens $\mathrm{Y}$. Is the combination of immunotherapy and radiotherapy in non-small-cell lung cancer a feasible and effective approach? Front. Med. 6, 244 (2019).

69. Ishihara D, Pop L, Takeshima T, Iyengar P, Hannan R. Rationale and evidence to combine radiation therapy and immunotherapy for cancer treatment. Cancer Immunol. Immunother. CII. 66(3), 281-298 (2017).

70. Lehrer EJ, Peterson J, Brown PD et al. Treatment of brain metastases with stereotactic radiosurgery and immune checkpoint inhibitors: an international meta-analysis of individual patient data. Radiother. Oncol. J. Eur. Soc. Ther. Radiol. Oncol. 130, 104-112 (2019).

71. Wang Y, Deng W, Li N et al. Combining immunotherapy and radiotherapy for cancer treatment: current challenges and future directions. Front. Pharmacol. 9, (2018).

72. Socinski MA, Jotte RM, Cappuzzo F et al. Atezolizumab for first-line treatment of metastatic nonsquamous NSCLC. N. Engl. J. Med. 378(24), 2288-2301 (2018).

73. Loganadane G, Dhermain F, Louvel G et al. Brain radiation necrosis: current management with a focus on non-small-cell lung cancer patients. Front. Oncol. 8, 336 (2018).

74. Besse B, Le Moulec S, Mazières J et al. Bevacizumab in patients with nonsquamous non-small-cell lung cancer and asymptomatic, untreated brain metastases (BRAIN): a nonrandomized, Phase II study. Clin. Cancer Res. Off. J. Am. Assoc. Cancer Res. 21(8), 1896-1903 (2015).

75. Rini BI, Plimack ER, Stus V et al. Pembrolizumab plus axitinib versus sunitinib for advanced renal-cell carcinoma. N. Engl. J. Med. [Internet]. 380(12), 1116-1127 (2019).

76. Rini BI, Powles T, Atkins MB et al. Atezolizumab plus bevacizumab versus sunitinib in patients with previously untreated metastatic renal cell carcinoma (IMmotion151): a multicentre, open-label, Phase III, randomised controlled trial. Lancet Lond. Engl. 393(10189), 2404-2415 (2019).

77. Motzer RJ, Penkov K, Haanen J et al. Avelumab plus axitinib versus sunitinib for advanced renal-cell carcinoma. N. Engl. J. Med. 380(12), 1103-1115 (2019).

78. Khair DO, Bax HJ, Mele S et al. Combining immune checkpoint inhibitors: established and emerging targets and strategies to improve outcomes in melanoma. Front. Immunol. 10, (2019).

79. Hu-Lieskovan S, Moon J, Campos D et al. Reversing resistance to PD-1 blockade by combination of talimogene laherparepvec (T-VEC) with pembrolizumab (pembro) in advanced melanoma patients following progression on a prior PD-1 inhibitor: SWOG S1607 (NCT\#02965716). J.Clin. Oncol. 36(Suppl. 15), TPS9603 ( 2018).

80. Blake Z, Marks DK, Gartrell RD et al. Complete intracranial response to talimogene laherparepvec (T-Vec), pembrolizumab and whole brain radiotherapy in a patient with melanoma brain metastases refractory to dual checkpoint-inhibition. J. Immunother. Cancer. 6(1), 25 (2018).

81. Camidge DR, Lee EQ, Lin NU et al. Clinical trial design for systemic agents in patients with brain metastases from solid tumours: a guideline by the Response Assessment in Neuro-Oncology Brain Metastases working group. Lancet Oncol. 19(1), e20-e32 (2018).

82. Doherty MK, Jao K, Shepherd FA, Hazrati L-N, Leighl NB. Central nervous system pseudoprogression in a patient treated with PD-1 checkpoint inhibitor. J. Thorac. Oncol. Off. Publ. Int. Assoc. Study Lung Cancer. 10(10), e100-101 (2015).

83. Okada H, Weller M, Huang R et al. Immunotherapy response assessment in neuro-oncology: a report of the RANO working group. Lancet Oncol. [Internet]. 16(15), e534-e542 (2015).

-• Proposal for response assessment in the brain in ICI-treated patients.

84. Galldiks N, Lohmann P, Werner J-M, Ceccon G, Fink GR, Langen K-J. Molecular imaging and advanced MRI findings following immunotherapy in patients with brain tumors. Expert Rev. Anticancer Ther. 20(1), 9-15 (2020).

85. Spain L, Walls G, Julve M et al. Neurotoxicity from immune-checkpoint inhibition in the treatment of melanoma: a single centre experience and review of the literature. Ann. Oncol. Off. J. Eur. Soc. Med. Oncol. 28(2), 377-385 (2017). 
